PONTIFÍCIA UNIVERSIDADE CATÓLICA DO RIO DE JANEIRO

\title{
League of Legends e Marketing de Experiências: Um estudo exploratório
}

\author{
Nicolas Braga Abou Jaoude
}

Centro de CIÊnCIAS SOCIAIS - CCS

DEPARTAMENTO DE ADMINISTRAÇÃO

Graduação em Administração de Empresas 


\section{Nicolas Braga Abou Jaoude}

\section{League of Legends e Marketing de Experiências: Um estudo exploratório}

Trabalho de Conclusão de Curso

Trabalho de Conclusão de Curso, apresentado ao programa de graduação em Administração da PUC-Rio como requisito parcial para a obtenção do título de graduação em Administração.

Orientadora: Alessandra Baiocchi A. Corrêa Rio de Janeiro, junho de 2017. 
"É muito melhor arriscar coisas grandiosas, alcançar triunfos e glórias, mesmo expondo-se a derrota, do que formar fila com os pobres de espírito que nem gozam muito nem sofrem muito, porque vivem nessa penumbra cinzenta que não conhece vitória nem derrota" - Theodore Roosevelt 


\section{Agradecimentos}

Primeiramente, gostaria de agradecer a minha já falecida e querida mãe Tania Maria Braga Abou Jaoude, por todo o apoio e dedicação que me deu em todos os seus anos de vida, por me mostrar como a vida é bela e que sempre devo acreditar nos meus sonhos.

Ao meu querido e amado pai, Antoine Kozhaya Abou Jaoude, que lutou e ainda luta todos os dias pelo meu sucesso, que me mostrou que a determinação é a chave de todo o sucesso e que o "bom sempre vai ganhar", me fazendo permanecer em pé, firme e forte, mesmo nas horas e dias mais difíceis.

Um agradecimento especial ao meu irmão, Antoine Braga Abou Jaoude, que além de sempre servir como uma inspiração para mim, por me ajudar na conquista de todos os meus sonhos, inclusive na minha grande vitória em conseguir uma bolsa integral nesta tão admirada universidade, cujo não teria conseguido sem sua ajuda.

Aos meus irmãos, Ralph Antoine Abou Jaoude, Adrian Antoine Abou Jaoude e Daniel Antoine Abou Jaoude, que sempre me deram os melhores conselhos possíveis e sempre estiverem meu lado em todos os momentos. E a toda família Braga e Abou Jaoude.

Aos professores Sergio Bruni e Augusto Sampaio, que me ajudaram muito em minha jornada nesta universidade e que confiaram e acreditaram em todo meu empenho e esforço e a todos os meus amigos e irmãos de alma, que não só sempre me apoiaram, como me inspiram todos os dias para alcançar ainda mais meus sonhos e ir cada vez mais longe. Em especial um forte abraço ao meu querido amigo Leonardo Soares por todo o apoio neste trabalho.

Por fim, agradeço a todos os professores que pude ter ao longo dos meus 23 anos de vida, e que também me ajudaram e guiaram nessa jornada que eu passei pela universidade, especialmente à minha querida mestra Alessandra Baiocchi, que além de orientadora e amiga, sempre será um exemplo pessoal e profissional para mim, distribuindo sorrisos e simpatia aonde quer que passe e sendo uma excelente profissional. Também gostaria de agradecer especialmente ás professoras Mila Viana, Lygia Magacho, Renata Kurtz, Cláudia Duarte Ana Cláudia Pinheiro, Veranise Dubeux, Léa Mara, Andréa Cherman e Renata Machado e aos professores Roberto Gil Uchoa e Marco Aurélio, cujo os ensinamentos, orientações e lições de vida que pude adquirir com todos eles, ao longo de todo este tempo na universidade, são de valor inestimável e que muito do profissional que sou hoje é devido a vocês. Como diria Augusto Cury: "Professores brilhantes ensinam para uma profissão. Professores fascinantes ensinam para a vida. ", sem dúvida alguma, vocês ensinaram para a vida. Muito obrigado. 


\title{
Resumo
}

Jaoude, Nicolas. Rio de Janeiro, 2017. Trabalho de Conclusão de Curso Departamento de Administração. Pontifícia Universidade Católica do Rio de Janeiro.

Este trabalho tem como objetivo investigar como o jogo League of Legends pode ser utilizado por empresas que procuram atingir o público jovem através de ativações de marcas em eventos. Para isso foi realizado um estudo de observação direta no evento "Surrender Party", além de entrevistas e levantamento de dados secundários. Como resultado, foi percebido que o público de League of Legends é fiel, engajado e envolvido com a sua marca e parece ser atraído por eventos bem organizados, com características de League of Legends. Os achados também apontam uma demanda por mais eventos temáticos no Rio de Janeiro. Ademais, as ferramentas de marketing de experiências em eventos, sobretudo relacionados ao League of Legends foram bem recebidas no público pesquisado.

\section{Palavras chave}

League of Legends, Marketing de Experiências, Eventos.

\begin{abstract}
Jaoude, Nicolas. Rio de Janeiro, 2017. Trabalho de Conclusão de Curso Departamento de Administração. Pontifícia Universidade Católica do Rio de Janeiro.
\end{abstract}

This work aims to investigate how the game League of Legends, can be used by companies that seek to reach the young public, through brand activations in events. For this, a direct observation study was conducted at the "Surrender Party" event, aswell as interviews and secondary data collection. As a result, it has been noticed that the League of Legends public is loyal, engaged and involved with their brand and seems to be attracted to well-organized events with League of Legends features. The findings also point to a demand for more themed events in Rio de Janeiro. In addition, the marketing tools of experience in events, mainly related to the League of Legends were well received in the researched public.

\section{Key-words}

League of Legends, Experience marketing, Events. 


\section{Sumário}

1. Apresentação do tema e objetivos do estudo 1

1.1 Introdução - O mercado de games no Brasil e no mundo 1

1.2 perfil do público gamer brasileiro e dados sobre o League of Legends

1.3 Objetivo Final $\quad 7$

1.4 Objetivos intermediários 8

1.5 Delimitação e foco do estudo 8

$\begin{array}{ll}1.6 \text { Oportunidade e relevância do estudo } & 8\end{array}$

2. Referencial Teórico 9

2.1 Entretenimento e o consumo de jogos eletrônicos 9

2.2 Envolvimento do consumidor e comunidades de marca 9

$\begin{array}{ll}\text { 2.3 Marketing de experiências } & 12\end{array}$

3. Passos metodológicos 14

$\begin{array}{ll}3.1 \text { Tipo de pesquisa } & 14\end{array}$

$\begin{array}{ll}3.2 \text { Etapa } 1 & 14\end{array}$

3.3 Etapa 2 - Observação direta 15

3.4 Etapa 3 - Entrevistas qualitativas $\quad 15$

3.4.1 Fontes de informação e seleção de sujeitos 15

4 Análise da Pesquisa de Campo 16

4.1 Observação direta - O evento "Surrender Party" 16

$\begin{array}{ll}4.2 \text { Análise das entrevistas } & 19\end{array}$

5. Recomendações e considerações finais 26

6. Referências Bibliográficas 28

$\begin{array}{ll}\text { 7. Anexo } 1 & 31\end{array}$ 


\section{Lista de figuras}

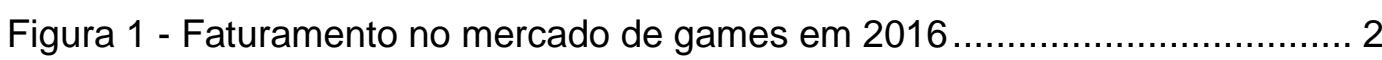

Figura 2 - Crescimento das Receitas dos E-sports pelo mundo .......................... 3

Figura 3 - Categorias dos jogos eletrônicos ................................................. 4

Figura 4 - Perfil demográfico (sexo) do público Gamer no Brasil ........................ 5

Figura 5 - Faixa etária do público gamer no Brasil............................................ 5

Figura 6 - Imagem do campeonato de meio de temporada MSI no Brasil em 2017

Figura 7 - Imagem da Skin personalizada "DJ Sona" da personagem Sona...... 17

Figura 8 - Imagem de fã fantasiada de Cosplay na Surrender Party ................ 18

Figura 9 - Final da Oceanic Pro League ...................................................... 20

Figura 10 - Final Norte-Americana dos Campeonatos Acadêmicos................... 22

Figura 11 - Imagem de fãs fantasiados de cosplay na final do campeonato brasileiro de League of Legends (CBLoL) ............................................. 25 


\section{Apresentação do tema e objetivos do estudo}

\subsection{Introdução - O mercado de games no Brasil e no mundo}

O mercado mundial de games é um dos mercados que mais cresce no mundo, movimentou 99,6 bilhões de dólares em 2016 e possui uma projeção de movimentar 118,6 bilhões de dólares até 2019 (NEWZOO, 2016). É um mercado com grande potencial de expansão no Brasil, país que ocupa o 11ำ lugar no ranking de maior mercado de games no mundo, movimentando cerca de 900 milhões de reais em 2015 (ECOMMERCE, 2016).

A maior parte do crescimento desta indústria encontra-se na Ásia, representando $58 \%$ do total de crescimento global e $47 \%$ do faturamento global (U\$ 46.6 bilhões) segundo relatório de pesquisa realizada pela NEWZOO em 2016 (Figura 1). 


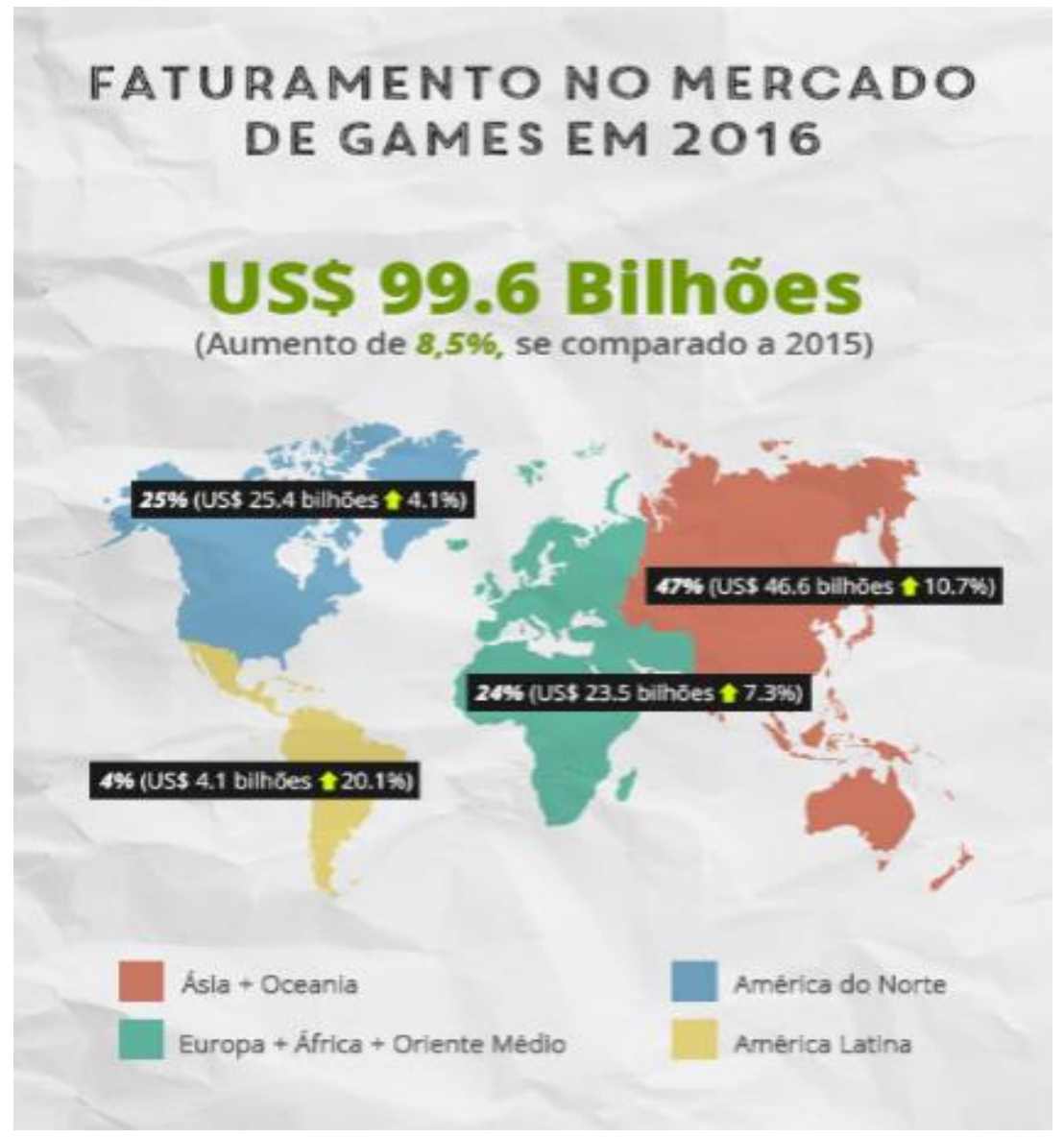

Figura 1 - Faturamento no mercado de games em 2016

Fonte: Newzoo Global Games Market Report, 2016, página 10.

No Brasil, o crescimento da indústria de games faz com que cada vez mais empresas queiram entrar nesse grande mercado, principalmente devido à popularização de smartphones e tablets.

Segundo pesquisa divulgada em 2014 pelo NPGT (Núcleo de Política e Gestão Tecnológica da USP), são cerca de 61 milhões de brasileiros usuários de jogos online e eletrônicos, incluindo todas as categorias de games, jogos para computadores, consoles, smartphones e tablets. (Pág 40).

Além do crescimento da indústria de jogos no mundo, também é válido mencionar o crescimento elevado do mercado de "E-sports" (esportes eletrônicos), com campeonatos de nível global e que movem um grande mercado global. Segundo um estudo feito pela Superdata Research em 2016, o 
crescimento das receitas dos E-sports pelo mundo tem previsão de chegar a 1,23 bilhões de dólares até 2019, conforme consta na Figura 2.

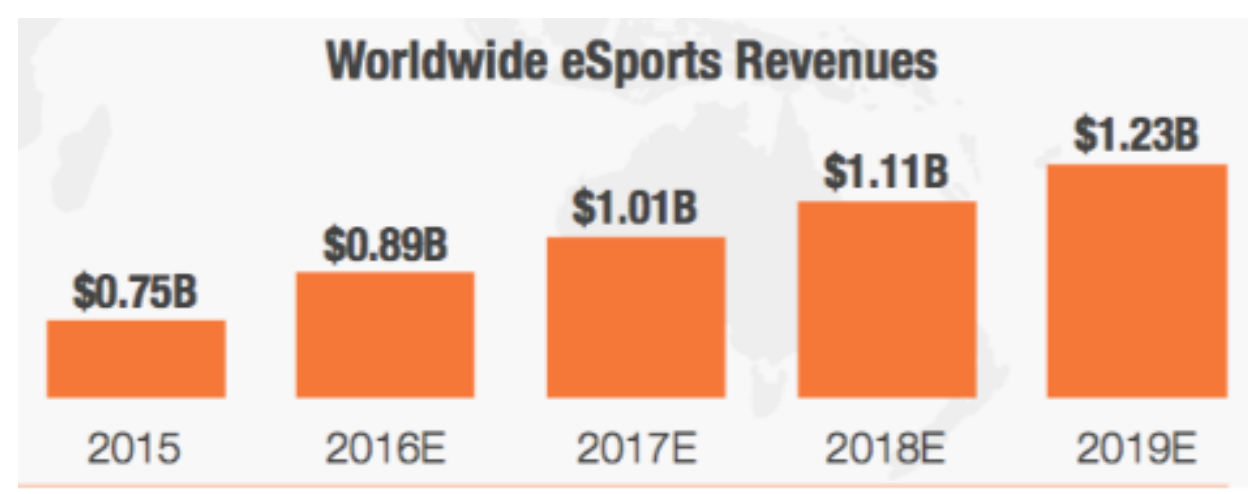

Figura 2 - Crescimento das Receitas dos E-sports pelo mundo

Fonte: Superdata Research, 2016, página 4

No Brasil o mercado de E-sports está cada vez mais popular devido principalmente à vinculação deste conteúdo em grandes mídias atuais, tais como os canais pagos SporTV e ESPN que possuem em suas programações conteúdos exclusivamente dedicados ao universo dos E-sports, além da transmissão dos principais campeonatos e eventos no mundo (SporTV, 2017).

Levando em consideração o faturamento anual de 99,6 bilhões de dólares de 2016 (NEWZOO Global Games Report, 2016), e de acordo com o mesmo relatório, o mercado de games pode ser segmentado em quatro grandes categorias, separadas pela plataforma que seus consumidores usam e pelo seu percentual sobre o faturamento do ano de 201 : $32 \%$ jogos para PC, $29 \%$ jogos para consoles (videogames), $27 \%$ smartphones e $12 \%$ tablets, tendo a maior taxa de crescimento a categoria de jogos para smartphones, com crescimento anual de $23,7 \%$ e com a maior tendência de crescimento para os próximos anos (Figura $3)$. 


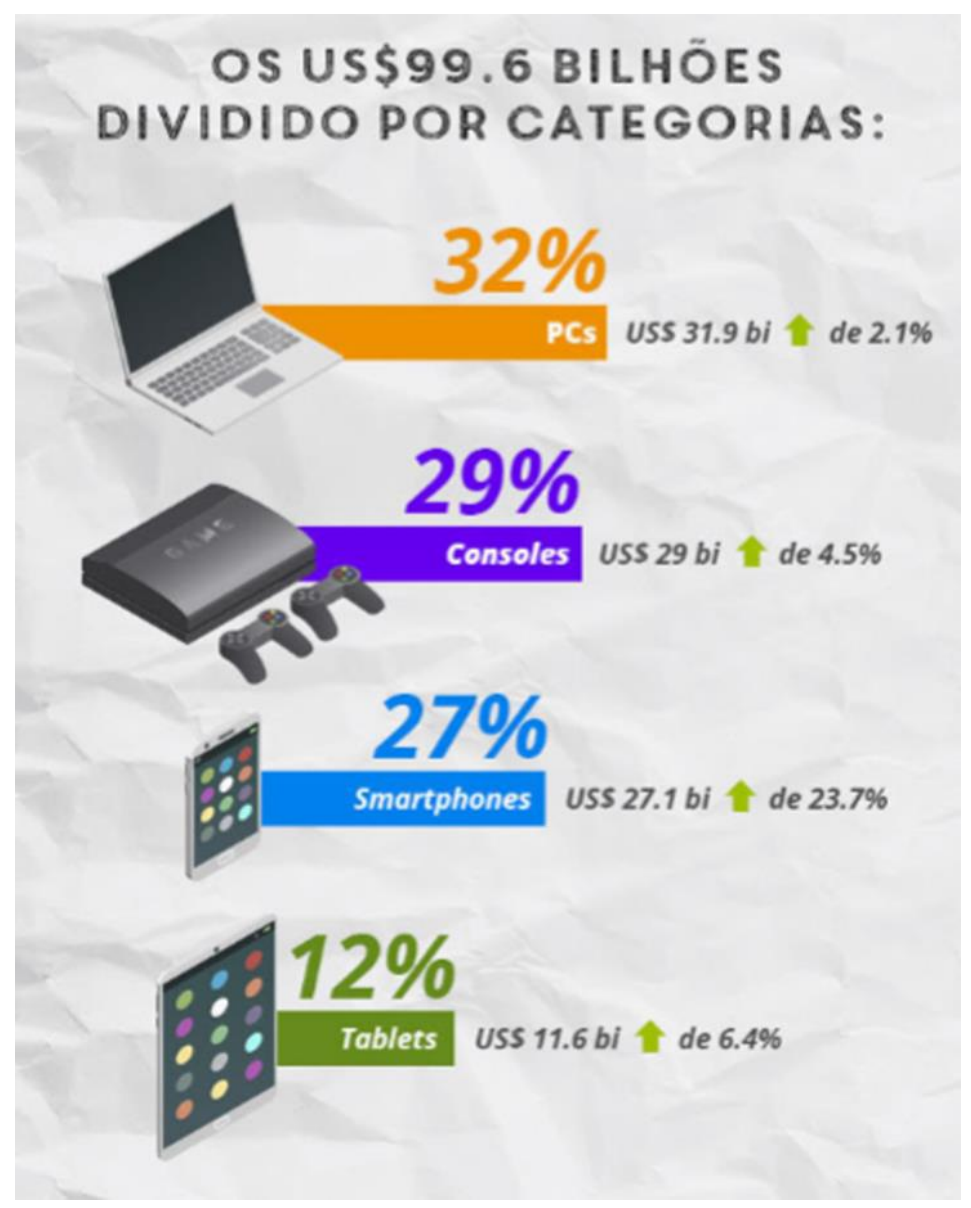

Figura 3 - Categorias dos jogos eletrônicos

Fonte: Newzoo Global Games Market Report, 2016, página 12.

\subsection{0 perfil do público gamer brasileiro e dados sobre o League of Legends}

Em relação ao público gamer, o Brasil é o $12^{\circ}$ país na lista de maiores consumidores de jogos no mundo, apresentando 60,5 milhões de jogadores online, representando $29,7 \%$ da população total do país em 2016 , sendo que $56 \%$ do total de gamers gastam dinheiro nos jogos, segundo dados do relatório global de games realizado pela Newzoo em 2016.

Em relação ao sexo do público gamer no Brasil, 53,6\% do público é composto pelo sexo feminino (Pesquisa Game Brasil, 2017). Ademais, o 
crescimento do público feminino nos jogos se dá em um ritmo bastante acelerado: em 2013 o público feminino era de $41 \%$ e apresentou um crescimento de 12,6\% em apenas 4 anos (Figura 4).

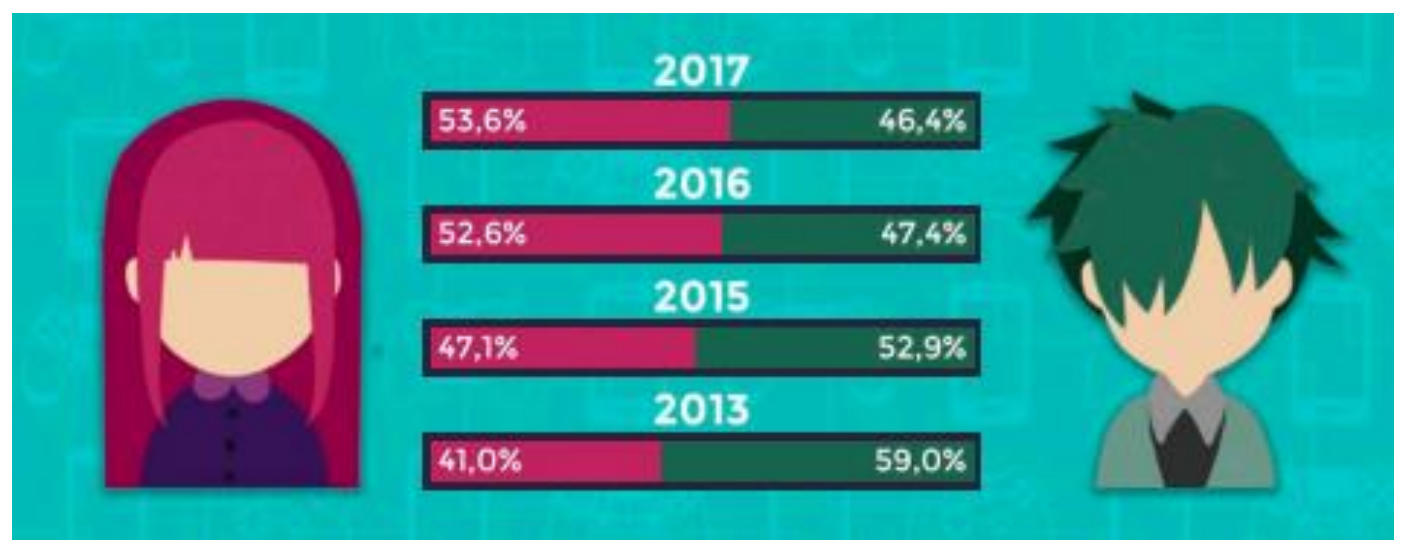

Figura 4 - Perfil demográfico (sexo) do público Gamer no Brasil

Fonte: Pesquisa Game Brasil 2017, página 8.

Referente à faixa etária desse público no Brasil, a maior parte tem de 25 a 34 anos, representando um total de $36,2 \%$ do público total de gamers no Brasil, e $28,4 \%$ de 16 a 24 anos (Pesquisa Game Brasil, 2017) (Figura 5).

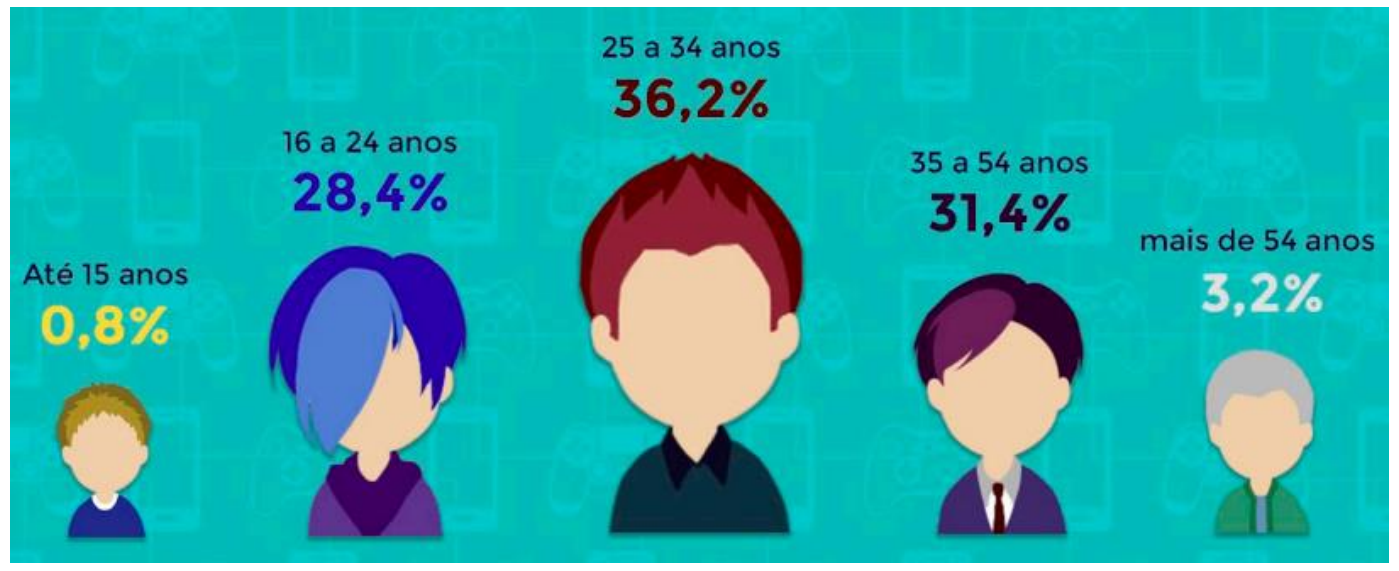

\section{Figura 5 - Faixa etária do público gamer no Brasil}

Fonte: Pesquisa Game Brasil 2017, página 9. 
Ainda em relação ao público gamer no Brasil, 74\% do público joga em mais de um dispositivo, sendo denominado um público com perfil multiplataforma, isto é, quando se joga em mais de um dispositivo ao mesmo tempo. As plataformas mais utilizadas são os mobiles $(37,6 \%)$, videogames em segundo lugar $(28,8 \%)$ e em terceiro lugar os computadores $(26,4 \%)$, segundos dados da Pesquisa Game Brasil, 2017.

Segundo estudo realizado pela Super Data em 2016, os jogos de computador mais lucrativos no mundo são em 1ํㅡ no ranking o League of Legends (LoL), com faturamento de 1,7 bilhões de dólares, seguido de Dungeon Fighter e Crossfire, ambos com 1,1 bilhões de dólares.

O foco deste estudo será o League of Legends, pois além de ser o mais lucrativo dos jogos, apresentando um rápido crescimento desde do seu surgimento, também é um dos que mais tem maior representatividade no Brasil, com transmissões de seus campeonatos e eventos em grandes emissoras de televisão, tais como a ESPN e SporTV e com números cada vez mais expressivos no Brasil e no mundo.

Atualmente, apenas no League of Legends, são mais de 100 milhões de usuários mensais ativos no mundo, o que representa mais de $1 \%$ da população da terra online todos os meses (IGN, 2016). Segundo a sua produtora, Riot Games, em 2014, apresentava 27 milhões de jogadores ativos todos os dias (Estadão, 2016). Ademais, o campeonato mundial de League of Legends 2016 foi transmitido por 23 emissoras em 18 línguas diferentes, com premiação de 6,7 milhões de dólares para os times que disputaram a final, segundo dados da própria empresa, o que demonstra seu grande mercado (Riot Games, 2016). 


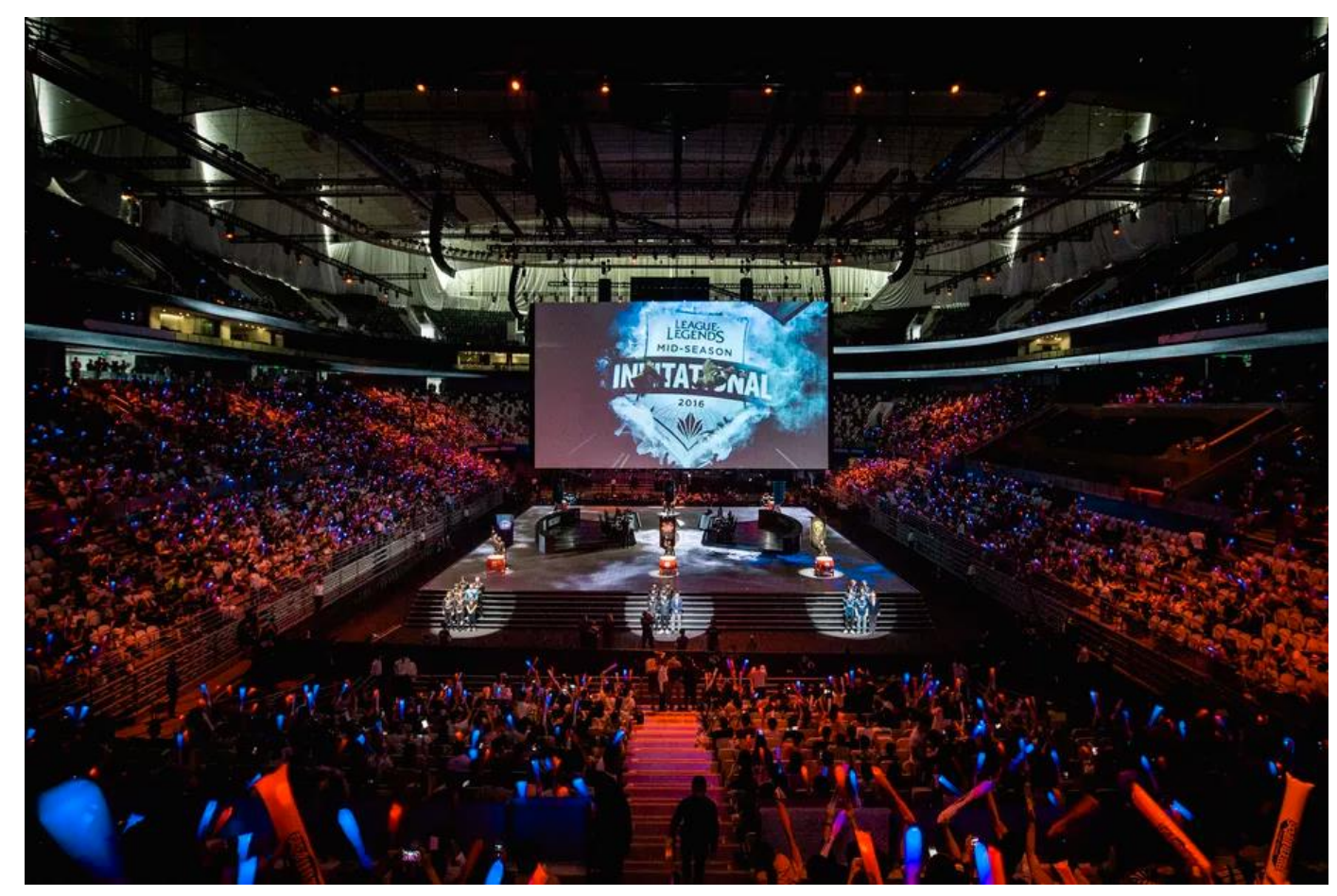

Figura 6 - Imagem do campeonato de meio de temporada MSI no Brasil em 2017

Fonte: Rift Herald

Diante deste contexto, este trabalho busca responder à seguinte questão: Como as empresas poderiam usar ferramentas de marketing de experiências para se aproximar do público jovem brasileiro, consumidor de League of Legends?

\subsection{Objetivo Final}

O objetivo final deste estudo é investigar o público consumidor de League of Legends, de maneira com que empresas tenham a possibilidade de utilizar o marketing de experiências para alcançar este público. 


\subsection{Objetivos intermediários}

Para alcançar o objetivo final, os seguintes objetivos intermediários deverão ser atingidos:

- O que atrai o público de League of Legends para os eventos?

- O que o público de League of Legends valoriza na experiência?

- O que afastaria o público de League of Legends da experiência?

- Quais elementos sensoriais estão presentes nos eventos envolvendo o público de League of Legends?

\subsection{Delimitação e foco do estudo}

Em relação à delimitação do estudo, haverá uma abordagem do ponto de vista dos consumidores de League of Legends, com foco no público jovem e adulto, na faixa entre 16 e 34 anos, que é equivalente a $65 \%$ do público gamer no Brasil (Pesquisa Game Brasil, 2017).

O período estudado será o ano de 2017, entre os meses de maio a novembro, com o público da cidade do Rio de Janeiro.

\subsection{Oportunidade e relevância do estudo}

O crescimento dos E-sports, que inclusive faz parte da programação de canais renomados esportivos, nacionais e internacionais, como o SporTV e a ESPN, sugere que os profissionais de marketing se beneficiariam ao conhecer melhor seu público.

Este estudo também pode ser relevante para as empresas atuantes no segmento de jogos eletrônicos em geral e empresas que buscam alcançar ainda mais o público jovem com o uso de estratégias relacionadas ao marketing de experiências. Além disso, pode ser interessante para profissionais de outras áreas, sobretudo profissionais da área de marketing que buscam entender melhor sobre o uso do marketing de experiências em campanhas de marketing e outras maneiras de utilizá-lo para alcançar o público jovem.

Em relação à relevância acadêmica, este trabalho pode colaborar na literatura sobre o marketing de experiências como ferramenta para alcançar o público jovem, sobretudo em relação ao universo de games, mais especificamente, League of Legends. 


\section{Referencial Teórico}

\subsection{Entretenimento e o consumo de jogos eletrônicos}

Segundo Trigo (2003, p. 32), o entretenimento é "divertido, fácil, sensacional, irracional, previsível e subversivo". O consumidor brasileiro cada vez mais busca se entreter de formas distintas na atualidade, com um mercado extremamente rápido e com mudanças radicais a todo o momento, é cada vez mais difícil para os consumidores acompanharem as movimentações e novidades deste novo cenário.

O ser humano é atraído não só pela satisfação nos bens de consumo, mas também pela simulação e "materialização" de seus desejos e sonhos. Sendo assim, podemos relacionar este ponto com a ideia de simular e tentar trazer os sonhos e desejos dos consumidores o mais próximo de uma realidade, usando como exemplo, jogos eletrônicos para alcançar este objetivo (Krüger, 2004, p. 3).

A indústria de games no Brasil e no mundo não lucra somente com a venda finalizada dos jogos, mas lucra principalmente com a venda de itens pós compra e itens que são denominados bens virtuais, definido por Rebs (2012, p.207) como "itens ou elementos formados por pixels que vinculam valores capitais para a sua aquisição" , esses itens muitas vezes são comprados com o intuito dos indivíduos se destacarem nos jogos e também de se socializarem e fazerem parte de determinados grupos dentro dos jogos, o que mostra que o fator de sociabilização dentro do universo online é muito relevante.

Estes itens podem muitas vezes serem utilizados como estratégias de marketing das empresas para se relacionarem de forma mais intrínseca com seus consumidores, tendo um contato menos "agressivo" e com menos chances de se tornar negativo para determinada marca.

\subsection{Envolvimento do consumidor e comunidades de marca}

Segundo Solomon (2016, p. 39), envolvimento é a "relevância do objeto percebida por uma pessoa com base em suas necessidades, valores e 
interesses", onde objeto seria referência a um produto ou a uma marca, anúncio ou a uma situação de compra.

Há diferentes fatores que criam envolvimento e estes fatores podem estar relacionados a pessoa, objeto ou situação. De forma mais sucinta, podemos dizer que o envolvimento do consumidor com a marca é o quanto de interesse o consumidor tem em determinada marca, produto ou em uma situação de compra. Quanto mais as empresas conseguirem vincular suas marcas nos consumidores, maior será o envolvimento deles com elas.

Além da influência de suas culturas, subculturas e classes sociais, ou consumidores também são influenciados em suas decisões de compra pelos grupos de referência que, segundo CHURCHILL \& PETTER (2012, p.160) são "grupos de pessoas que influenciam os pensamentos, sentimentos e comportamentos de um consumidor".

Existem diversos tipos de grupos de referência, como família, amigos, clubes ou organizações profissionais. Existem grupos de referência primários, que são aqueles em que temos contato direto, face a face com os membros ou secundários, como por exemplo uma associação comunitária, que podem influenciar o indivíduo, mas não promovem contato face a face entre todos os membros.

No caso dos jovens, principal público do presente estudo, ele é muito influenciado pelo ambiente onde vive e na maioria das vezes ele tem por referência seu grupo de amigos, o que influenciam em suas decisões e hábitos de consumo.

"A interconectividade da rede de computadores através da internet, ao aliar-se com o caráter lúdico dos games, traz consigo uma experiência diferente ao jogar um game, dando a possibilidade de resolver problemas e desafios em conjunto"

(THOMAZ, 2011, p.12).

Uma das ferramentas de maior conectividade entre as pessoas no mundo contemporâneo é a internet e os games estão conectando pessoas, sobretudo aqueles que são do gênero Massive Multiplayer Online (MMO), ou seja, grupos que formam comunidades virtuais de jogadores e criam novos laços sociais (Mazurek, 2013, p.5).

Ao falarmos do conceito de sociabilidade e das novas comunidades virtuais que cada vez mais são utilizadas como meio de interconectividade entre as 
pessoas, podemos reafirmar uma noção da ideia de jogo defendida por Huizinga (2007, p.7) que afirma que "o jogo possui, inerentemente, função social", além disso, o jogo em relação ao conceito de sociabilidade, pode ser entendido como "forma pura, isenta de substância, sentido e interpretação por si só; mas ainda assim, uma interação social lúdica, relaxante e agradável por excelência" (SALGADO, 2011, p 26). Pode-se entender que socializar seria algo lúdico, que permite o desprendimento das obrigações, deveres e seriedade da vida real, que permite todo um novo ambiente e simulação na mente dos diversos jogadores de jogos online (Mazurek, 2013, p.5).

Já segundo KOTLER \& KELLER (2012, p.270), comunidade de marca "é uma comunidade especializada de consumidores e funcionários cuja identificação e atividades giram em torno da marca". São três características que identificam as comunidades de marca segundo KOTLER \& KELLER (2012, p.270): (a) "Consciência de espécie" ou senso de conexão para com a marca, a empresa, o produto ou outros membros da comunidade; (b) Rituais, histórias e tradições compartilhadas que ajudam a transmitir o significado da comunidade e (c) uma responsabilidade ou um dever moral compartilhado tanto à a comunidade como um todo quanto a seus membros individuais. 


\subsection{Marketing de experiências}

Marketing de experiências, segundo Smilansky (2009, Página 5), é definido como:

O processo de identificação e satisfação das necessidades e aspirações dos consumidores, de forma rentável, cativandoos através de uma comunicação bidirecional que dão vida às personalidades da marca e criam valor para o público-alvo.

O marketing de experiências está em voga no mundo contemporâneo por se mostrar uma ferramenta útil e na maioria das vezes com um custo benefício melhor do que formas tradicionais de reter clientes, como por exemplo com ações de brindes e prêmios tradicionais (EXAME, 2010), assim elas preferem utilizar o marketing de experiências, para conquistar e fidelizar seus clientes.

SCHMITT (1999, p.1) categoriza os diferentes tipos de experiência em que os consumidores podem ter em 5 grupos. (a) Experiências sensoriais; (b) experiências afetivas; (c) Experiências criativas-cognitivas; (d) Experiências físicas, comportamentais e ligadas ao estilo de vida; (e) Experiências de identidade social que resultam de um grupo de referência ou cultura.

Além disso o marketing de experiências possui 4 características principais, segundo SCHMITT (1999, p.57), (a) Foco nas experiências dos clientes, ou seja, ir além dos benefícios funcionais que determinado produto ou serviço pode oferecer, pensando em como podemos fornecer valores sensoriais, emocionais, cognitivos, comportamentais ou relacionais que podem agregar ou substituir os valores funcionais; (b) Foco no consumo como uma experiência holística, ou seja, ir além do fato de simplesmente consumir determinado produto ou serviço. Um exemplo que SCHMITT (1999, p. 58) traz em seu estudo que:

Os comerciantes que usam o marketing experiencial não pensam "shampoo, creme de barbear ou secador de cabelo e perfume", ao invés disso eles pensam na experiência de tomar banho" e aí se perguntam como estes produtos, suas embalagens e suas propagandas, antes de seu consumo, podem melhorar a experiência de consumo.

Indo muito além do simples fato de consumir determinado produto ou serviço; (c) Os consumidores são racionais e emocionais, denotando que os consumidores não só tomam decisões usando seu lado racional do cérebro, 
mas sim usando também seu lado emocional, pensando muitas vezes nas emoções ou sentimentos que aquele determinado produto ou serviço pode oferecer, por exemplo; (d) Os métodos e ferramentas são ecléticos. Ao contrário do marketing tradicional que em sua maioria utiliza metodologias analíticas, quantitativas e verbais, os métodos e ferramentas utilizados no marketing experiencial são diversas, em suma, ele não está vinculado a uma ideologia metodológica, é eclético, podendo ter ferramentas e métodos altamente analíticos e quantitativos, como podem ser mais intuitivos e qualitativos, da mesma forma que podem ser utilizados formas verbais ou visuais como ferramentas e métodos, variando tudo conforme o objetivo da estratégia utilizada. 


\section{Passos metodológicos}

\subsection{Tipo de pesquisa}

Este estudo caracteriza-se como pesquisa de natureza exploratória, realizada por meio observação direta e entrevistas pessoais com roteiro semiestruturado. O roteiro da pesquisa realizada com os consumidores encontrase no anexo 1. Segundo CHURCHILL \& PETER (2012, p.126)

Quando os pesquisadores procuram descobrir ideias e percepções, eles conduzem uma pesquisa exploratória. Em geral, a pesquisa é usada para gerar hipóteses ou explicações prováveis e identificar áreas para um estudo mais aprofundado.

Os tipos de coleta de dados utilizadas foram: pesquisa com dados secundários, entrevistas pessoais e observação direta de experiências. $O$ tipo de pesquisa utilizado foi de cunho qualitativo, uma vez que o grupo em pesquisa é restrito e assim pode-se aprofundar nos detalhes das entrevistas e com o objetivo de compreender o público e descobrir como utilizar os dados coletados, principalmente para área empresarial.

O período estudado foi entre os meses setembro e novembro no ano de 2017 , com foco no público do Rio de Janeiro, sendo que os entrevistados foram recrutados por acessibilidade, com idade entre 16 anos e 34 anos.

\subsection{Etapa 1}

Nesta etapa houve a revisão de literatura relevante para o tema e uma contextualização sobre o tema de pesquisa. Ela foi realizada principalmente por meio de fontes secundárias, possibilitando a análise dos assuntos que envolvem a questão em pauta. Desta investigação foram desenvolvidas as seções: Entretenimento e o consumo de jogos eletrônicos, envolvimento do consumidor, comunidades de marca e marketing de experiências. 


\subsection{Etapa 2 - Observação direta}

Logo após a etapa 1, foi realizado um trabalho de observação direta em um evento com a temática de League of Legends. O evento escolhido foi a "Surrender Party", que ocorreu no dia 30 de setembro de 2017, na Lapa, centro do Rio de Janeiro, no espaço Duplex Club. O evento teve duração total de 7 horas e contou com a participação de cerca de 700 pessoas. Nesta ocasião, foi possível observar características do evento e entrevistar informalmente no local 14 pessoas.

Antes da ida ao evento, foi elaborado um roteiro com todas as características que deveriam ser observadas, como iluminação, estrutura, vestimenta dos consumidores e dos funcionários do local, organização e ambientação. Além disso, foi pensado em observar aspectos subjetivos, tais como satisfação com o evento, nível de serviço, entre outros.

\subsection{Etapa 3 - Entrevistas qualitativas}

Por fim, foram realizadas entrevistas com consumidores de League of Legends que já frequentaram eventos relacionados ao jogo. Esta etapa está detalhada nas seções a seguir.

\subsubsection{Fontes de informação e seleção de sujeitos}

A pesquisa foi realizada por meio de entrevistas individuais com homens e mulheres entre 16 e 34 anos, que já compareceram em pelo menos um evento relacionado ao assunto de League of Legends ou que teve proposta baseada na temática de League of Legends. Foram realizadas seis entrevistas entre 05 de outubro e 29 de outubro de 2017. A seleção dos entrevistados foi realizada por conveniência, uma vez que o autor do estudo possui forte contato com a comunidade de League of Legends, dependendo apenas da disponibilidade dos entrevistados. Alguns dos escolhidos não puderam realizar a entrevista pessoalmente, por falta de tempo ou outros motivos. Nestes casos foram feitas entrevistas via Skype por vídeo, facilitando a comodidade de ambas as partes, tanto do entrevistador, como de seus entrevistados. 


\section{Análise da Pesquisa de Campo}

Neste capítulo serão expostos os achados da pesquisa de campo, incluindo a análise das entrevistas e o resultado da observação direta.

\subsection{Observação direta - O evento "Surrender Party"}

O evento ocorreu de 23:00 até 06:00 do dia 01 de outubro de 2017 e contava com a maior parte do seu público composto por jovens entre 18 e 27 anos. No local do evento também estava incluso chapelaria do próprio evento, vendas de copos personalizados, cartelas de RP (Riot Points, dinheiro utilizado dentro do próprio jogo) e também com a venda de um pacote VIP com acesso a mais regalias e ao camarote. Diversas características do evento foram customizadas para remeterem ao game, incluindo a entrada do evento, as roupas dos funcionários e algumas decorações pontuais dentro do evento, como por exemplo, a mesa do DJ que remetia a característica do personagem do jogo denominada "Sona" que possui uma skin (customização do personagem que pode ser comprada dentro do jogo) que é DJ (imagem ilustrativa abaixo). É importante salientar que os organizadores proibiram fotografias no evento e entrevistas após as 02 horas da manhã, acreditando que a pesquisa poderia incomodar os participantes que ali estavam para uma festa. 


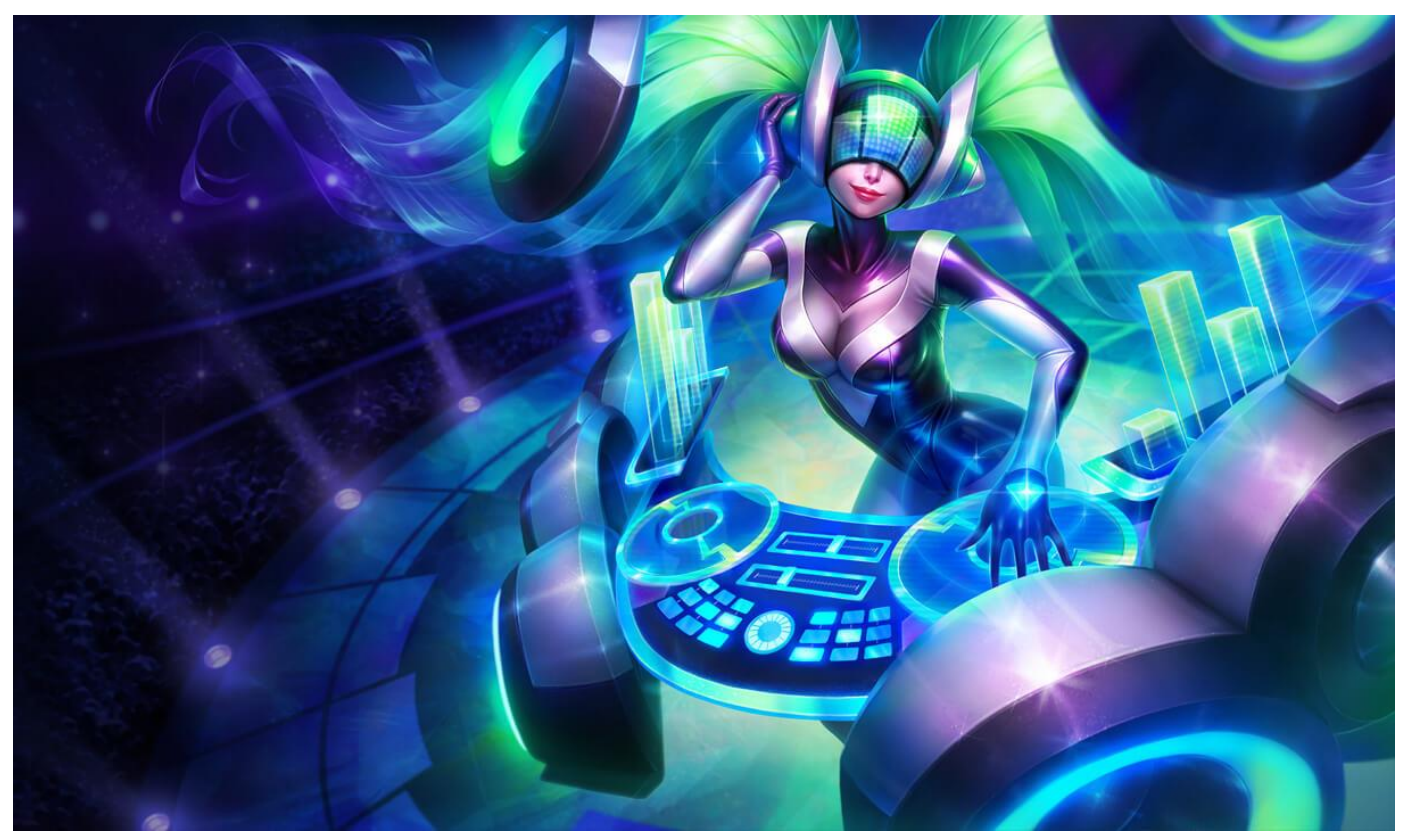

Figura 7 - Imagem da Skin personalizada "DJ Sona" da personagem Sona

Fonte: Riot Games

O evento era temático, utilizando como base diversas características do jogo, desde de nomes de personagens, até customizações como o som, por exemplo. Já envolvendo o marketing de experiências e sensorial, desde seu início, foi observado sons que remetiam ao jogo, como por exemplo a música temática do jogo ou sons característicos do mesmo. Além disso, o evento contou com diversos atrativos para os seus consumidores, incluindo bebida liberada de diversos tipos, bebidas customizadas com relação ao tema do evento, fazendo referência ao jogo com personagens e características do jogo e chapelaria no local.

Durante o evento, alguns convidados foram abordados rapidamente, por cerca de 3 minutos em média. Foram 14 pessoas, todas, bastante empolgadas e felizes com o evento e muito satisfeitos com toda a sua produção. Um deles declarou:

"fazia muito tempo que eu não ia em um evento tão bom assim, amanhã irei virar a noite jogando LOL depois de hoje." 
O que mostra o entusiasmo e a fidelização à marca de seus consumidores. Em alguns momentos do evento o DJ do evento realizou algumas ativações da marca "Catuaba Selvagem", realizando questionários para os voluntários que subirem no palco e distribuindo brindes para os vencedores relacionados à marca.

Foi observado neste evento que os consumidores pareciam usufruir uma experiência positiva, podendo ocorrer uma associação favorável com as marcas envolvidas no evento e também com o jogo League of Legends.

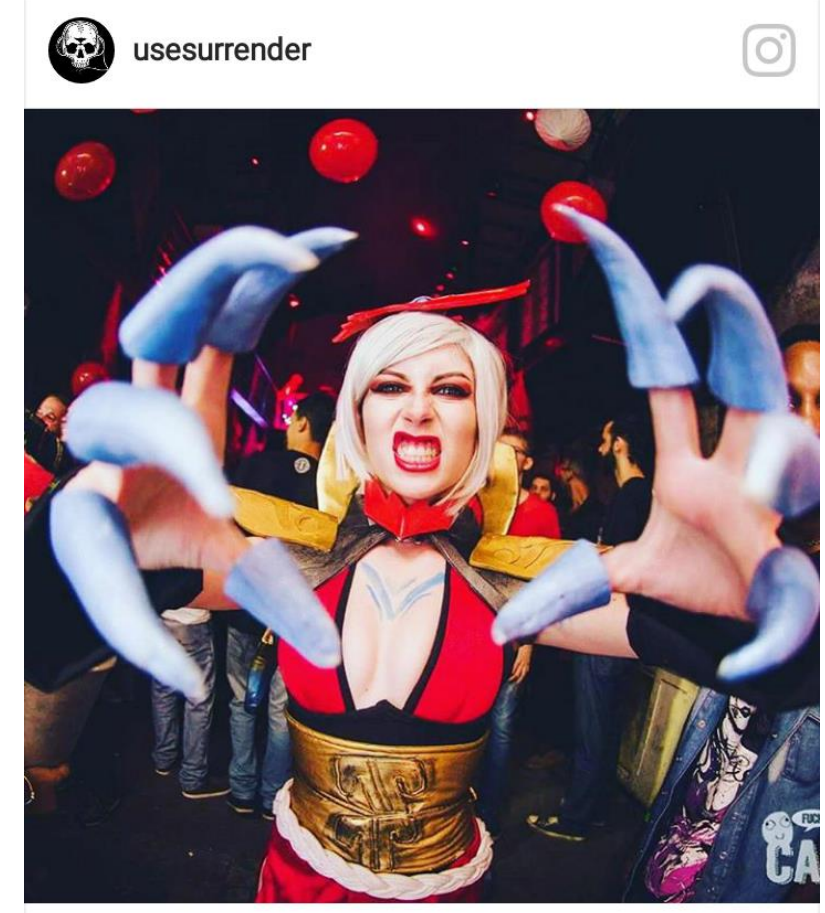

usesurrender \#SurrendeRParty

Figura 8 - Imagem de fã fantasiada de Cosplay na Surrender Party Fonte: Instagram Usesurrender 


\subsection{Análise das entrevistas}

Com o intuito de analisar as entrevistas, todo o estudo foi separado em 3 tópicos para melhor compreensão e entendimento da pesquisa. Os tópicos criados foram:

(a) A influência da comunidade de marca de League of Legends; (b) $\mathrm{O}$ envolvimento dos consumidores de League of Legends com a sua marca; (c) Os eventos relacionados ao League of Legends e a experiência de seus consumidores

\subsubsection{A influência da comunidade de marca de League of Legends e a} experiência dos consumidores

Nas entrevistas realizadas pode-se perceber que existem diferentes tipos de influências para se começar a jogar League of Legends. Pode-se perceber que existem pessoas que começaram a jogar $L o L$ por influência de terceiros, seja da comunidade da marca ou de pessoas próximas, como namorados ou amigos próximos. Este tipo de influência é muito normal no mundo virtual, reafirmando o conceito que Huizinga (2007, p.7) define: "o jogo possui, inerentemente, função social". Uma citação de uma das pessoas entrevistas que tem referência a isso é:

"Eu comecei a jogar LoL principalmente por dois motivos: Primeiro porque eu realmente gostei do perfil e tipo de jogos pois eu não o conhecia e achei muito diferente do convencional da época que comecei a jogar (2013) e também porque alguns amigos próximos a mim jogavam e meu namorado na época. Então, como eu queria me manter próxima a eles e socializar ainda mais com eles, resolvi começar a jogar também."

(Entrevistada 1- Light User) 
Isto evidencia que existem diferentes tipos de motivações para os consumidores jogarem League of Legends e a forte influência que os grupos de referência e a comunidade de marca têm sobre seus consumidores, além do forte apego e fidelização de seus consumidores com a sua marca.

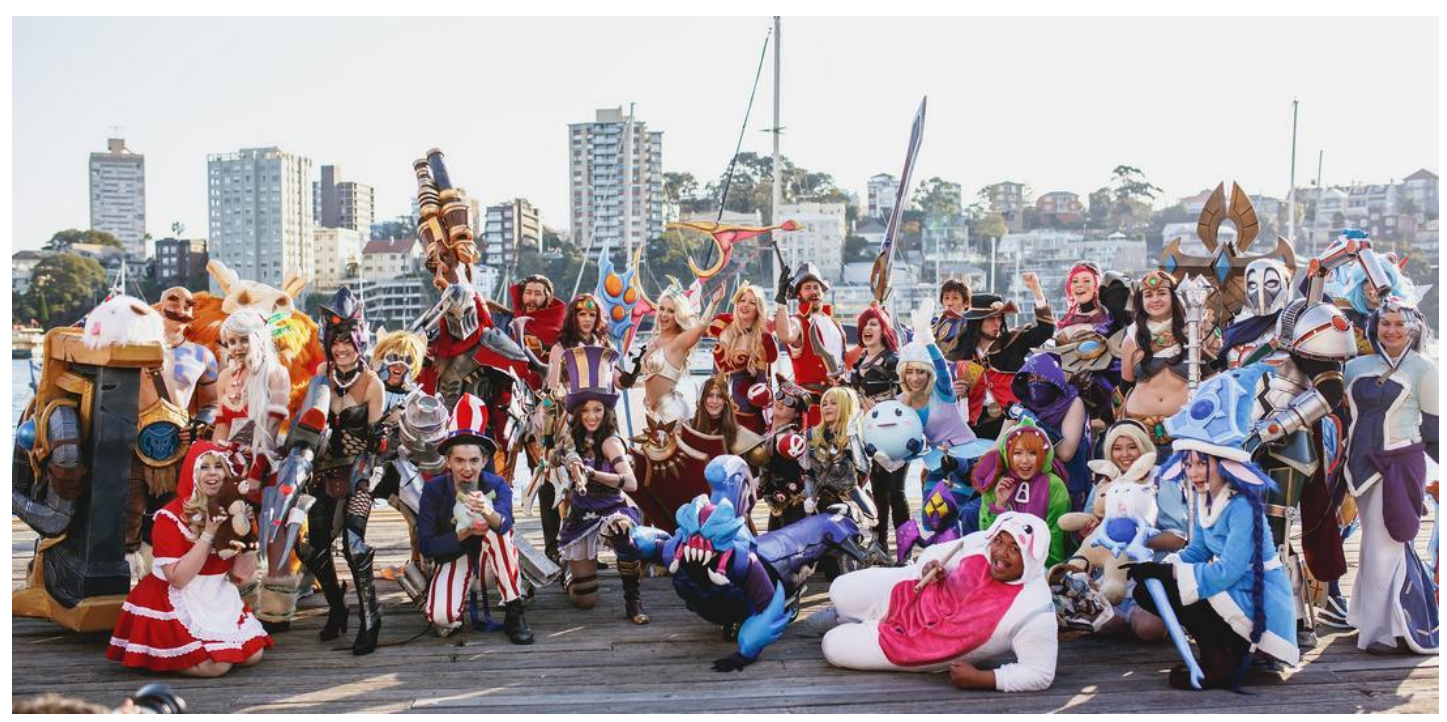

Figura 9 - Final da Oceanic Pro League

Fonte: League of Legends

\subsubsection{O envolvimento dos consumidores de League of Legends com a} sua marca

Os entrevistados foram separados em dois grupos de consumidores. Os Light users, aqueles que jogam menos de 6 horas por semana e os Heavy users que são aqueles que jogam mais de 6h por semana. Os Light users entrevistados demonstraram um forte apego pela marca e pelo jogo, mostrando a sua fidelidade a marca, a ponto de não jogarem outros jogos pois acham apenas o LoL interessante e não tem interesse em conhecer outros jogos, mesmo que não o joguem com tanta frequência como os Heavy users.

Já os Heavy users demonstraram uma paixão muito forte pela marca e um nível de fidelização quase que exclusivo ao League of Legends. Todos os Heavy users do presente estudo começaram a jogar por influência da forte comunidade de League of Legends ou porque amigos muito próximos jogavam e influenciaram estes a jogarem também, mostrando mais uma vez a força da 
comunidade em relação ao número de novos usuários no jogo e a grande influência dos grupos de referência neste contexto.

Ao ser questionado do porquê de tanta paixão pelo League of Legends, um entrevistado Heavy user respondeu:

Pois é um jogo muito único. Já joguei diversos jogos e nunca achei um tão bom assim, nem mesmo o DOTA 2, nenhum se compara ao LoL. Uma comunidade extremamente unida e que todos os dias trabalham juntos para melhorar e desenvolver o jogo não tem preço. Além disso, alguns dos meus melhores amigos atualmente eu conheci através do LoL. Inclusive um deles é de Curitiba e vamos nos ver no final do ano pela primeira vez! Teve uma época que eu falava mais com ele pelo Skype do que com amigos próximos no meu dia a dia na faculdade. (Entrevistada 2 - Heavy User)

Ao serem questionados se já foram em algum evento relacionado à marca, a frequência de ida em eventos, os entrevistados disseram que já foram em mais de 1 evento relacionado à temática de League of Legends.

Quando questionados sobre o que fez eles irem ao evento relacionado ao LoL pela primeira vez e sobre o que acharam, os entrevistados disseram que compareceram devido ao forte apego pelo jogo e pela influência de amigos e/ou da comunidade em relação aos eventos do jogo.

Eu amo League of Legends! Acho o jogo incrível. Porém, o que eu mais gosto são os eventos relacionados a marca, tudo sempre temático e incrível. Sempre me reúno com amigos, até mesmo que conheci dentro do jogo, para ir nos eventos e sempre gostamos muito. No último que fui, fui fantasiado de Garen (personagem do jogo) e gostei muito. (Entrevistada 3 - Heavy User) 
O envolvimento dos consumidores entrevistados com a marca é muito forte e é ainda mais fortalecido quando se trata da sua comunidade de marca. Os entrevistados disseram que comunidade de $L o L$ é muito boa e influencia muito em sua percepção sobre a marca, dizendo ainda que este é um dos principais motivos para com o seu amor sobre o jogo.

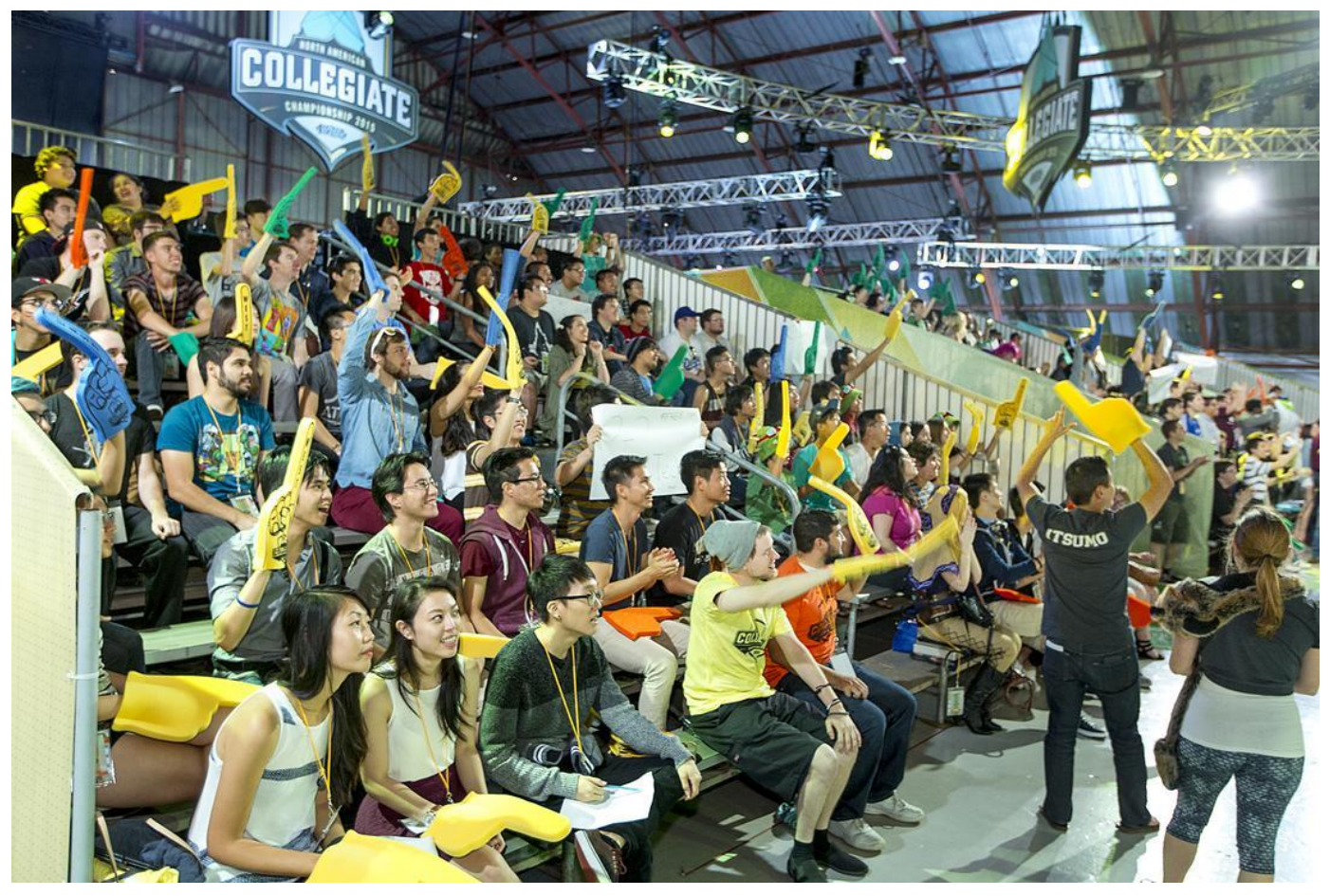

Figura 10 - Final Norte-Americana dos Campeonatos Acadêmicos

Fonte: League of Legends

\subsubsection{Os eventos relacionados ao League of Legends e a experiência} de seus consumidores.

Quando questionados sobre suas experiências em eventos com temática ou referência ao League of Legends, os entrevistados destacaram que o evento ser temático ou ter relação com o LoL foi decisivo em sua tomada de decisão de ida ao evento demonstrando a grande influência que o jogo tem sobre suas tomadas de decisão em relação a ida em eventos.

Os entrevistados indicam que o que mais chamou a atenção nos eventos que foram, foi justamente as experiências que tiveram dentro do mesmo, todas relacionadas ao LoL diretamente. 
Cara, foi incrível! Desde do primeiro momento que entrei no evento eu já pude perceber como seria incrível a experiência. Logo na entrada do evento estava tocando a música temática de abertura de LoL e isto me chamou muita a atenção. Muitas pessoas fantasiadas de Cosplay e ainda pude ter a experiência de encontrar o Kami (renomado jogador de LoL brasileiro) pessoalmente.

(Entrevistada 4 - Heavy User)

Já em relação a outras marcas em eventos do LoL, os entrevistados disseram que acham muito legal a ideia da marca de realizar um evento relacionado à temática de League of Legends, sendo que se o evento for minimamente bem organizado, sua percepção sobre determinada marca será aprimorada. Porém, caso o evento não seja bem organizado em geral, a percepção sobre determinada marca irá cair drasticamente.

Por último, quando questionados sobre como as marcas podem melhorar ou prejudicar suas imagens utilizando o League of Legends, disseram que gostam quando as marcas inovam ou são criativas. Por exemplo, uma sugestão de um dos entrevistados foi:

"Pô cara, imagina se eu vejo um cara fantasiado de Doutor Mundo (personagem do jogo, conhecido por ser um personagem musculoso e grande) fantasiado oferecendo Whey protein? (suplemento para musculação) em alguma entrada de loja de suplementos!?! Cara, eu compraria na hora sem pensar!! E olha que sou gordo, sedentário e não malho. (risos)." (Entrevistada 5 - Heavy User) 
Os entrevistados fizeram sugestões de como podemos utilizar o marketing de experiências para promover as marcas, que será mais detalhado no capítulo 5 do estudo.

Já em relação a prejudicar suas marcas, disseram que somente se acontecerem "erros" em relação ao jogo:

\begin{abstract}
"Imagina se eu chego no evento ou no lugar sei lá e eles fazem uma analogia errada com o jogo? Por exemplo, escrevem o nome de algum personagem errado ou usam coisas passadas (que não existem mais no jogo) no evento? Eu ficaria irritado e iria embora na hora, pois para mim é o mínimo que a organização acerte nos detalhes e características que o jogo possui. Como eles vão fazer um evento sobre um jogo que não o conhecem? É o mínimo né, pelo menos. " (Entrevistada 6 - Light User)
\end{abstract}

Outra citação, agora em relação a como utilizar o marketing de experiências em um determinado evento:

"Eu gostaria muito que tivesse um evento que todos fossem obrigados a irem fantasiados de personagens do jogo e aonde houvesse uma "simulação" do jogo, com pessoais reais e valendo algum prêmio, com pessoas lutando entre si para ganhar e destruir o nexus (objetivo final do jogo) do inimigo na vida real, com brigas com espadas de isopor, música do jogo, narradores, entre outros. Se houvesse alguma marca que fizesse isso, eu seria além de eternamente grato, com certeza me tornaria consumidor da mesma." (Entrevistada 7 - Light User) 


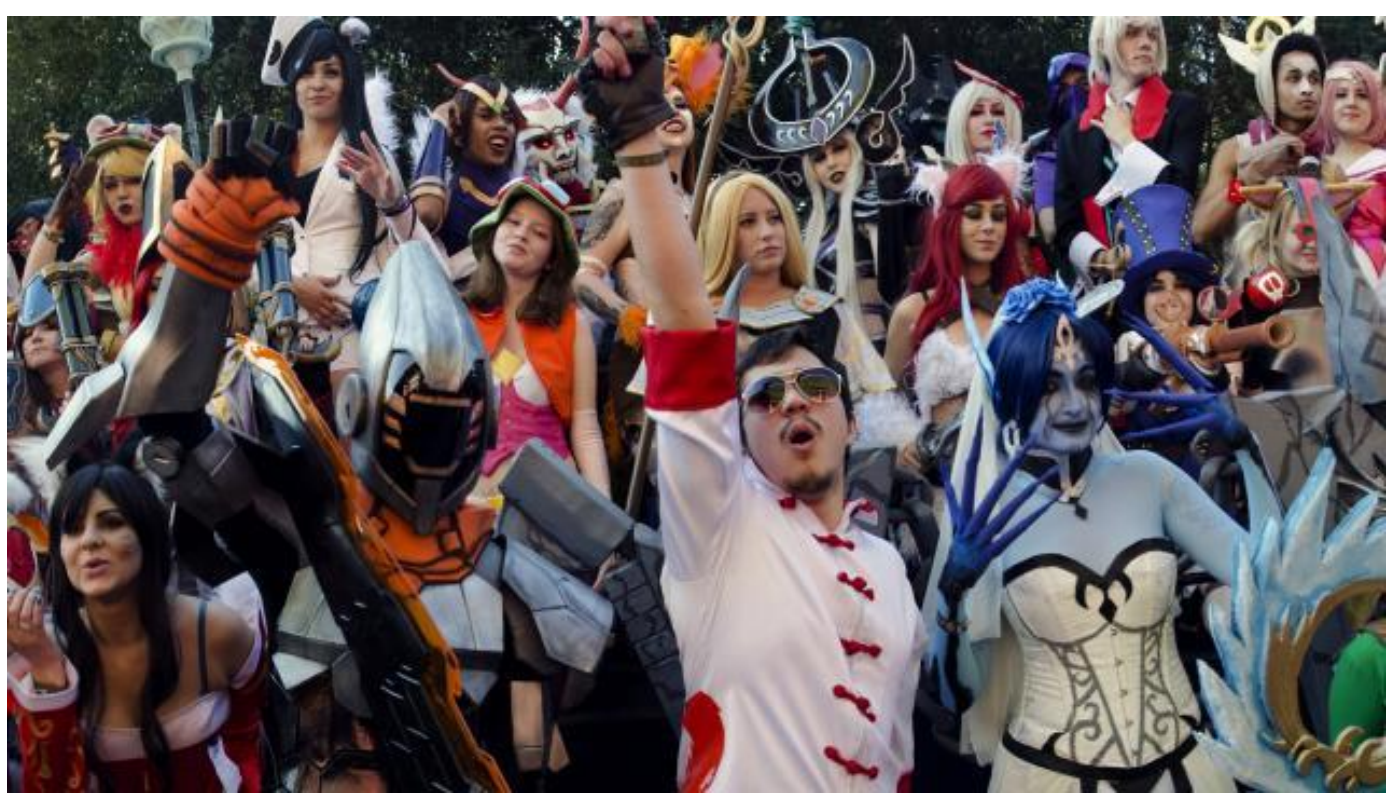

Figura 11 - Imagem de fãs fantasiados de cosplay na final do campeonato brasileiro de League of Legends (CBLoL)

Fonte: Riot Games - "As criações da comunidade na final do CBLoL 2016". 


\section{Recomendações e considerações finais}

O presente trabalho foi iniciado com propósito de investigar como as empresas podem utilizar o marketing de experiências, sobretudo em eventos, para alcançar o público jovem brasileiro, consumidor de League of Legends. Para a realização desta pesquisa, foi feito primeiramente uma revisão de literatura e realizada uma pesquisa com dados secundários para obter mais informações sobre o mercado do LoL se encaixa e para construção e elaboração do presente estudo. Após isso, foi realizada a pesquisa de observação direta no evento Surrender Party, seguida de entrevistas qualitativas para melhor entender o perfil do público.

O estudo sugere que o público de League of Legends é fiel, engajado e envolvido com a marca. O público de League of Legends parece ser atraído por eventos bem organizados, com características ou temática de League of Legends e valorizam a fidelidade do evento em relação à marca, ou seja, se o evento é condizente com as características do jogo sem nenhum tipo de erro ou engano.

Os entrevistados declararam que ainda sentem muita falta de eventos temáticos ou relacionados ao LoL e que as empresas poderiam utilizar muito esta lacuna de mercado para se promoverem e ainda dizendo que as empresas que utilizarem seriam muito bem vistas por eles, justamente por ainda não terem muitas que o realizam. Além disso, o público estudado se mostra amante da de sua marca e diz que a experiência de ir em um evento temático de League of Legends é muito positiva em relação as suas percepções de determinada marca.

Além disso, é importante salientar que dizer que quanto mais "sensorial" for a experiência realizada, como a utilização de sons, texturas personalizadas, eventos de Cosplay, entre outros, melhor será a percepção do evento para os seus consumidores e assim, maior a influência positiva sobre a marca realizadora do evento.

Recomenda-se que as empresas que desejam usar o marketing de experiência em eventos, busquem temas diferenciados e estratégias inovadoras, tais como novas temáticas ou analogias ou comparações com jogos online. Como por exemplo, utilizar personagens do jogo ilustrativos para promoção de seus produtos. 
O cenário favorável para a categoria de E-sports e o aumento exponencial de seu público, sobretudo jovens, sugere que o tema de League of Legends é interessante tanto para o mundo empresarial quanto acadêmico. Portanto, as empresas que buscam atingir esse público deveriam investir em estratégias ligadas ao League of Legends.

Por fim, é recomendado a elaboração de novos estudos sobre o assunto, tanto para fins acadêmicos, quanto para fins empresariais, uma vez que além de ser um assunto ainda muito recente, é também um assunto cada vez mais discutido atualmente. 


\section{Referências Bibliográficas}

Alvanista. Infográfico do mercado de games em 2016. 2016. Disponível em: < http://alvanista.com/manopanco/posts/3444851-infografico-do-mercado-degames-em-2016 > Acesso em 06 de junho de 2017.

CHURCHILL, Jr Gilbert A/Peter, J. Paul. Marketing - Criando Valor para os Clientes. São Paulo: Saraiva, 2012. 3ª Edição.

Ecommerce Brasil. A indústria de jogos eletrônicos, um setor em ascensão no Brasil. Rio de Janeiro, 2016. Disponível em: $<$ https://www.ecommercebrasil.com.br/noticias/industria-de-jogos-eletronicosum-setor-em-ascensao-no-brasil/ > Acesso em 27 de junho de 2017.

Estadão. League of Legends chega a $\mathbf{1 0 0}$ milhões de jogadores. São Paulo, 2016. Disponível em: < http://link.estadao.com.br/noticias/games,league-oflegends-chega-a-100-milhoes-de-jogadores,10000075949 > Acesso em 5 de novembro de 2017.

Exame. Empresas investem em marketing de experiência. Publicado em outubro de 2010. Disponível em: <

https://exame.abril.com.br/marketing/empresas-investem-experiencias-incentivarpublico-interno-599890/\# > Acesso em 07 de novembro de 2017.

FORBES. Riot Games Reveals 'League of Legends' Has 100 Million Monthly Players. 2016. Disponível em: < https://www.forbes.com/sites/insertcoin/2016/09/13/riot-games-reveals-league-oflegends-has-100-million-monthly-players/\#7312b7425aa8 > Acesso em 28 de junho de 2017.

G1. 'League of Legends' alcança 67 milhões de jogadores. Rio de Janeiro, 27 jan, 2014. Disponível em: <

http://g1.globo.com/tecnologia/games/noticia/2014/01/league-legends-alcanca67-milhoes-de-jogadores.html >. Acesso em: 21 de junho de 2017

HUIZINGA, Johan. Homo ludens: o jogo como elemento da cultura. $5^{a}$ edição. São Paulo: Perspectiva, 2007.

IGN. League of legends ultrapassa $\mathbf{1 0 0}$ milhões de usuários mensais ativos. Rio de Janeiro, 2016. Disponível em: < http://br.ign.com/league-oflegends/38355/news/league-of-legends-ultrapassa-100-milhoes-de-usuariosmensais >. Acesso em: 20 de junho de 2017.

KOTLER, Philip; KELLER, Kevin Lane. Administração de Marketing. 14. ed. São Paulo: Pearson, 2012. 
KRUGER, Fernando; MOSER, Giancarlo. O Marketing dos Jogos Eletrônicos. Trabalho apresentado à Sessão de Temas Livres do XXVIII Congresso Brasileiro de Ciências da Comunicação. 2004.

Lolesports. 2016 League of Legends World Championship By the Numbers. 2016. Disponível em: < http://www.lolesports.com/en_US/articles/2016-leaguelegends-world-championship-numbers > Acesso em: 18 de maio de 2017.

MAZUREK, Mike Akama;POLINOV, Beatriz. Bens virtuais em games online: Consumo e Publicidade em League of Legends. São Paulo, 2013.

Newzoo. The Global Games Market reaches $\$ 99.6$ billion in 2016, mobile generating 37. Abril, 2016. Disponível em: <37\%https://newzoo.com/insights/articles/global-games-market-reaches-99-6billion-2016-mobile-generating-37/>. Acesso em: 15 de maio de 2017.

NPGT. Mapeamento da Indústria Brasileira e Global de Jogos Digitais. São Paulo, 2014. Disponível em: < http://www.abragames.org/uploads/5/6/8/0/56805537/mapeamento_da_industria _brasileira_e_global_de_jogos_digitais.pdf> Acesso em: 4 de outubro de 2017.

Pesquisa Game Brasil. Perfil do Gamer Brasileiro. Brasil, 2017. Disponível em: $<$ https://www.pesquisagamebrasil.com.br/pesquisagamebrasilgratis>. Acesso em: 27 de junho de 2017.

REBS, Rebeca. Bens virtuais em social games. São Paulo: Revista Intercom, RBCC, v. 35, n. 2, p. 205-224, jul./dez. 2012. Disponível online em: http://www.portcom.intercom.org.br/revistas/index.php/revistaintercom/article/vie w/1451/1413

Rift Herald. MSI 2017: Live news, scores and updates from Brazil's LOL event. 2017. Disponível em: < https://www.riftherald.com/lolesports/2017/4/27/15452598/msi-2017-lol-news-scores-updates > Acesso em: 8 de outubro de 2017.

SALGADO, Marcelo. Sociabilidade em espaços digitais complexos de MMORPGs. Dissertação de Mestrado da Faculdade Cásper Libero, São Paulo, 2011.

SCHMITT, Bemd (1999); Journal of Marketing Management.

SMILANSKY, Shaz (2009); Experiential Marketing, A practical guide to interactive brand experiences. Disponível em: < http://psbm.org/Ebooks/Experiential\%20Marketing.pdf> Acesso em 3 de novembro de 2017.

SOLOMON, Michael R. O Comportamento do Consumidor - Comprando, possuindo e sendo. 11.ed. Porto Alegre: Bookman, 2016. 
SporTV. SporTV acerta parceria com a Riot e vai transmitir a temporada do CBLoL. $2017 . \quad$ Disponível em: < http://sportv.globo.com/site/games/noticia/2017/01/sportv-acerta-parceria-e-vaitransmitir-toda-temporada-de-league-legends.html > Acesso em 10 de julho de 2017.

Superdata Research Worldwide digital games Market Report. Estados Unidos, 2017. Disponível em: < https://www.superdataresearch.com/us-digital-gamesmarket/ >. Acesso em: 15 de junho de 2017.

Superdata Research. eSports Market Report. Estados Unidos, 2016. Disponível em: <https://www.superdataresearch.com/market-data/esports-market-brief/>. Acesso em: 16 de junho de 2017.

THOMAZ, Felippe. Companhias de outro mundo: um breve olhar sobre a sociabilidade em RPGs online. Salvador: Simpósio em tecnologias digitais e sociabilidade Sim Social, 2011.

TRIGO, Luiz Gonzaga Godoi. Entretenimento: uma crítica aberta. São Paulo: Senac, 2003. 


\section{Anexo 1}

\section{PESQUISA QUALITATIVA MONOGRAFIA NICOLAS JAOUDE - ROTEIRO}

\section{AQUECIMENTO}

- Apresentação do moderador

- Apresentação do tema: Falar que é sobre utilização do marketing de experiências para conquistar o público jovem de League of Legends. (Explicar o que é marketing de experiências e dar alguns exemplos práticos).

- Apresentação do entrevistado: nome, idade, onde mora, com que frequência joga League of Legends, quantas horas joga por dia e a quanto tempo joga.

\section{SOBRE EVENTOS RELACIONADOS AO LEAGUE OF LEGENDS}

- Você costuma ir com que frequência a eventos temáticos em geral?

- O que te levou a ir em um evento relacionado ao LoL pela primeira vez?

- O que mais te chamou a atenção no evento?

- O que você mais gostou no evento? E o que menos gostou?

- Teve alguma marca que realizou promoção no evento?

- Vêm alguma marca em sua mente quando você pensa em League of Legends? Por que essa?

\section{MARKETING DE EXPERIÊNCIAS EM EVENTOS DE LEAGUE OF LEGENDS E SEU USO EMPRESARIAL}

- No evento que você que é relacionado à temática de League of Legends, houve alguma atividade ou ferramenta de marketing de experiência (se necessário exemplificar para o entrevistado) aplicada nele? Caso positivo na resposta, isso colaborou ou não com a melhora na percepção de qualidade do evento?

- Caso você fosse em algum evento de alguma marca especifica e ela utiliza-se o League of Legends como ferramenta de sua estratégia de marketing, sobretudo utilizando o marketing de experiências ou analogias com o jogo em relação aos seus produtos, isto iria influenciar na sua percepção em relação a determinada marca de que maneira?

Positivamente ou negativamente?

- Como podemos melhorar a imagem da marca utilizando o League of Legends como ferramenta? E como prejudicar? 